\title{
O mercado, os artistas, os colecionadores e as instituições
}

\author{
ANA LETÍCIA FIALHO
}

\begin{abstract}
Ana Letícia Fialho é diretora do Departamento de Estratégia Produtiva da Secretaria da Economia da Cultura/MinC desde 2016. Doutora em Ciências da Arte e da Linguagem na EHESS/Paris. Mestre em Gestão Cultural pela Universidade de Lyon II e Bacharel em Direito pela UFRGS. Atuou em organizações como a Associação Brasileira de Arte Contemporânea, Instituto de Estudos Brasileiros/USP, Base7, Fórum Permanente, Fundação Iberê Camargo, Fundação Bienal do Mercosul, Museu Nacional Centro de Arte Reina Sofia, SEBRAE, SENAC, SESC, etc. É co-autora dos livros Sociologia das artes visuais no Brasil (SENAC, 2012), O valor da obra de arte (Metalivros, 2014), Outras histórias na arte contemporânea (Paço das Artes, 2016) e co-organizadora, com Leandro Valiati, do Atlas Econômico da Cultura Brasileira (UFRGS, 2017).
\end{abstract}




\begin{abstract}
RESUMO
O sistema da arte contemporânea no Brasil viveu recentemente um período bastante positivo, de grande visibilidade, dinamismo, expansão e internacionalização. Nesse processo, o crescimento do mercado e os interesses mobilizados por seus agentes (artistas, galeristas e colecionadores) parecem ter sido determinantes. Atualmente, o contexto nacional já não é tão favorável, a instabilidade política e a estagnação da economia estão afetando o campo da cultura, e há fortes indícios de retração dos investimentos públicos e privados no campo da arte contemporânea, enquanto o processo de internacionalização da produção e do mercado parece prosseguir. A fim entender o impacto dessas mudanças recentes na (re)configuração do sistema da arte no Brasil, neste artigo retomaremos dados de pesquisas que apontam para um forte desequilíbrio entre a esfera de produção, o mercado e as instituições.
\end{abstract}

\title{
- PALAVRAS-CAVE
}

Sistema da arte contemporânea, mercado de arte, internacionalização

\section{ABSTRACT}

The contemporary art system in Brazil has recently undergone a highly positive period, attaining greater visibility and dynamism and allowing for substantial expansion and internationalization. In this process, the active development of the market and the interests that were mobilized by its agents (artists, gallerists and collectors) have seemingly been decisive. At present the national context is not as favourable seeing as the increased political instability and the stagnation of the economy have exerted an adverse effect on the sphere of culture. There are clear signs of retraction in public and private investment in the contemporary art domain, and on the other hand, the processes of internationalization of production and of the market seem to be advancing at a steady rate. In order to understand the impact of recent changes on the (re)configuration of the art system in Brazil, this article will pick up and expand on the research data that points toward a significant imbalance between the sphere of production, the market and institutions.

\section{KEYWORDS}

Contemporary art system, art market, internationalization

É interessante observar como no Brasil o mercado de arte vem despertando um maior interesse por parte da mídia e do meio acadêmico, reflexo de um protagonismo assumido pelo setor no sistema das artes, mas é importante lembrar que este sistema é composto por quatro instâncias fundamentais, cujas dinâmicas são distintas mas relacionadas: a da produção, da reflexão crítica (histórica, crítica e curadoria), a institucional e o mercado. ${ }^{1}$

$\overline{1}$ MOULIN, Raymonde. L'artiste, I'institution et le marché. Paris: Flammarion, 1992. 
Em diferentes regiões do mundo, encontram-se sistemas de arte contemporânea funcionando, em linhas gerais, de acordo com essa estrutura, contudo o peso respectivo das instâncias, a forma como elas se relacionam e se complementam, assim como o seu grau de internacionalização podem diferir significativamente, e ainda existe uma clara hierarquia entre eles ${ }^{2}$. Isso porque a produção, a validação, a circulação e a comercialização da arte são fortemente determinadas pelos contextos em que se inscrevem, embora estejamos globalmente conectados. Em sistemas de arte consolidados, como os existentes em alguns países europeus e nos Estados Unidos, há um equilíbrio entre as diferentes instâncias, e todas ajudam para fomentar, validar, difundir e preservar a produção artística, contribuindo para a construção de narrativas e, em última instância, para a escrita de uma história da arte. Em sistemas menos consolidados, o círculo de reconhecimento nem sempre se completa, havendo situações em que o mercado, ante a fragilidade institucional e a ausência de políticas públicas consistentes, como no Brasil, assume função preponderante no fomento à produção, circulação e validação dos valores artísticos, o que pode limitar a experimentação, provocar certa instabilidade e alimentar modismos que dificilmente se mantêm no médio-longo prazo, ou, contrariamente, quando o mercado é incipiente e a esfera institucional é a única a absorver uma pequena parcela da produção, poucos artistas logram viver do próprio trabaIho.

O sistema da arte contemporânea no Brasil viveu recentemente um período bastante positivo, de grande visibilidade, dinamismo, expansão e internacionalização. A partir dos anos 2000 , observou-se o surgimento de novos equipamentos culturais; a multiplicação de exposições, residências artísticas e publicações (favorecidas por linhas de financiamento diversificadas, embora irregulares, como editais e prêmios públicos e privados); o crescimento do número de galerias e do volume de negócios gerados pelo mercado de arte (impulsionados pelo aumento da base de colecionadores); uma maior circulação e visibilidade de artistas e galerias brasileiros no exterior e uma crescente presença de artistas e outros agentes do circuito internacional no país.

$\mathrm{O}$ crescimento do mercado e os interesses mobilizados por seus agentes (artistas, galeristas e colecionadores) parecem ter sido determinantes nesse processo.

O contexto econômico favorável e a cena artística efervescente atraíram a atenção de agentes do circuito internacional, altamente competitivos e profissionalizados, em busca de oportunidades: instituições consagradas ampliaram a presença de colecionadores brasileiros em seus comitês de aquisição; museus internacionais passaram a procurar no Brasil recursos para viabilizar seus projetos expositivos (grandes exposições contaram com patrocínio de colecionadores e empresas brasileiras $\left.{ }^{3}\right)$; galerias estrangeiras se fizeram mais presentes nas feiras

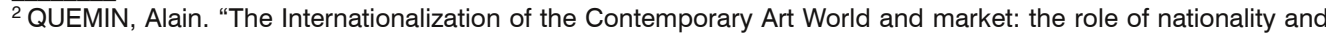
territory in a supposedly 'globalized sector"'. In LIND, Maria; VELTHUIS, Olav (orgs.). Contemporary art and its commercial markets: a report on current conditions and future scenarios. Berlin: Sternberg Press; Spanga: Tensta Konsthall, 2012, pp. 53-84.

${ }^{3}$ Como as retrospectivas dedicadas a Mira Schendel na Tate London (realizada de 25 de setembro de 2013 a 19 de janeiro de 2014) e a Lygia Clark no MoMA (realizada de 10 de maio a 24 de agosto de 2014).
} 
brasileiras $^{4}$ e mesmo uma grande marca do mercado internacional, a galeria White Cube, chegou a abrir uma filial em São Paulo em dezembro de 2012, fechando suas portas em 2015. Na direção contrária, observou-se o crescimento significativo da participação de galeristas no circuito internacional (sobretudo nas feiras internacionais de maior prestígio, mas também por meio de parcerias com outras galerias no exterior), e a presença de artistas brasileiros em exposições e coleções internacionais se ampliou.

Desde 2014, o contexto nacional já não é tão favorável, a instabilidade política e a estagnação da economia estão afetando fortemente o campo da cultura, e há fortes indícios de retração dos investimentos públicos e privados no campo da arte contemporânea $^{5}$. Já o processo de internacionalização da produção e do mercado parece prosseguir: noticia-se a crescente presença da arte brasileira em coleções públicas e privadas no exterior, assim como um aumento significativo das exportações por parte das galerias do mercado primário, da ordem de quase $100 \% \mathrm{em}$ $2015^{6}$. Um outro dado inédito e muito recente, é a abertura de filiais de galerias brasileiras no exterior?.

A fim de entender melhor o processo de reconfiguração do sistema da arte no Brasil em curso, para além de notícias esparsas e casos isolados que podem dar margem a generalizações e equívocos, cabe retomar dados coletados em pesquisas sobre o mercado e sobre as instituições, desenvolvidas nos últimos anos ${ }^{8}$, que apontam para um forte desequilíbrio entre a esfera de produção e o mercado de um lado, e a esfera institucional de outro.

\section{A pesquisa setorial Latitude sobre o mercado de arte contemporânea}

Em meados dos anos 2000, era nítida a impressão de que o mercado estava crescendo, mas não existiam dados objetivos que pudessem, de fato, mensurar ou atestar as determinantes desse desenvolvimento. Foi nesse contexto que surgiu a "Pesquisa setorial Latitude sobre o mercado de arte contemporânea no Brasil", sob

\footnotetext{
$\overline{{ }^{4} \mathrm{Em} \mathrm{2011}}$, a participação de galerias estrangeiras na SP Arte foi de 14 de um total de 89; já em 2012, foram 27 de um total de 110 galerias participantes; em 2013, 42 de 122; em 2014, 57 de 137; e em 2015, foram 55 de um total de 140 .

5 O Estado de São Paulo noticiou retração de até 50\% das vendas das galerias em 2015. Ver: GONÇALVES FILHO, Antônio. Arte para exportação. Estado de São Paulo, São Paulo, 21 de jan. de 2016. A Folha de São Paulo noticiou a queda das vendas das galerias e o corte orçamentário dos museus. Ver: FRIAS, Maria Cristina. Venda de obras de arte cai, mas preço se mantém. Folha de São Paulo, São Paulo, quarta-feira, 17 de fev. de 2016; MARTI, Silas. Crise força museus a cortar mostras e aumentar duração de exposições. Folha de São Paulo, São Paulo, 22 de mar. de 2016, disponível em: http://www1.folha.uol.com.br/ilustrada/2016/03/1752593-crise-forcamuseus-a-cortar-mostras-e-aumentar-duracao-de-exposicoes.shtml último acesso em: 20 de julho de 2016.

${ }^{6}$ Ver: GONÇALVES FILHO, Antônio, 2016, op. cit. e MACIEL, Nahima. Arte exportação. Correio Brasiliense, Brasília, Domingo, 14 de fev. de 2016.

7 FLAMINGO, Juliana. Em movimento inédito, galerias paulistanas abrem filiais no exterior. Veja, 01 de jul. de 2016. Disponível em: http://vejasp.abril.com.br/materia/galerias-de-arte-paulistanas-exterior e ALZUGARAY, Paula. Galeria Nara Roesler abre filial em Nova lorque. Lançamento oficial será durante a Armory Show 2016, em março. Select, São Paulo, 21 de jan. de 2016. Disponível em: http://www.select.art.br/start-spreading-the-news/ Último acesso em 01/07/2016.

${ }^{8}$ A Pesquisa Setorial Latitude sobre o mercado de arte contemporânea; a Pesquisa sobre a Economias das exposições e a Pesquisa sobre o colecionismo institucional, cujas referências completas encontram-se na bibliografia.
} 
minha coordenação até a sua quarta edição, publicada em 2015 ${ }^{9}$. O universo contemplado pela pesquisa era composto por cerca de 50 galerias de arte contemporânea que fazem parte da ABACT (Associação Brasileira de Arte Contemporânea). Trata-se, portanto, de uma fração do mercado, onde o mercado secundário não está representado, nem o primário em sua totalidade.

Ainda assim, seu conteúdo permite entender melhor como funciona o segmento do mercado que trabalha com os artistas em atividade e também, em certa medida, como o mercado se relaciona com outras instâncias do sistema ${ }^{10}$.

Desde a publicação dos primeiros resultados, em 2012, chamam atenção os dados que atestam um crescimento significativo do volume de negócios gerados pelo setor entre 2010 e 2014 (impulsionado sobretudo pelos colecionadores privados brasileiros, responsáveis por mais de $70 \%$ do volume de negócios realizados pelas galerias), assim como os que falam de uma crescente internacionalização das galerias e dos artistas por elas representados. Entre 2010 e 2013, por exemplo, a taxa média de crescimento das galerias ficou acima de $20 \%$ ao ano. Mesmo em 2014, já em um contexto econômico muito menos favorável, mais de metade das galerias pesquisadas afirmou ter aumentado seu volume de negócios em comparação aos anos anteriores. A partir de 2015, o quadro parece ter mudado, e muitas galerias relataram ter havido uma retração das vendas para o mercado nacional ${ }^{11}$.

Os negócios internacionais por sua vez cresceram em volume e houve uma diversificação não só de países de destino das vendas, mas também das instituições internacionais que adquiriram obras das galerias brasileiras. Os dados disponíveis sobre as exportações indicam um aumento constante nos últimos anos, tendo chegado a quase $100 \%$, passando de US\$ 34 em 2014 para US\$ 67 milhões em $2015^{12}$.

\footnotetext{
$\overline{9}$ Trata-se de uma pesquisa encomendada pela Associação Brasileira de Arte Contemporânea (ABACT) no âmbito do Projeto Latitude, em uma parceria entre a ABACT e a Apex-Brasil, que visa a internacionalização do mercado primário de arte contemporânea. Os relatórios das 4 edições encontram-se disponíveis em: http://latitudebrasil.org/pesquisa-setorial/ Último acesso em: 01/07/2016.

${ }^{10}$ Entre os aspectos abordados pela pesquisa estão: o perfil das galerias, que trata da diversidade tipológica e de suas diferenças geracionais e regionais; a escala, onde se encontram dados sobre faturamento, infraestrutura, número de artistas representados, número de exposições, número de trabalhadores, média salarial, participação em feiras; o modus operandi, que destaca as principais atividades das galerias, as características administrativo-financeiras, as formas de relacionamento com os artistas, parceiros e colaboradores, a relação com o mercado secundário e as dificuldades enfrentadas para a expansão dos negócios; os indicadores de crescimento do setor, que trazem informações sobre as vendas, tipos de obras negociadas, preços, principais plataformas de negócio, perfil de colecionadores; e, por fim, a inserção internacional, que trata dos diferentes aspectos relacionados à internacionalização das galerias, como a representação de artistas estrangeiros, estratégias de internacionalização, volume de vendas para o exterior, inserção internacional dos artistas representados em instituições internacionais, etc.

${ }^{11}$ A 5 a edição da Pesquisa Setorial Latitude, não mais sob a coordenação da autora, não foi publicada em sua integralidade. Dados parciais podem ser acessados em: http://media.latitudebrasil.org/uploads/arquivos/arquivo/2016-pesquisa-s.pdf .

12 Dados oficiais divulgados pela APEX-Brasil e pelo Projeto Latitude, disponível em: http://www.apexbrasil.com.br/Noticia/PROJETO-LATITUDE-E-APEX-BRASIL-ANUNCIAM-AUMENTO-RECORDE. Último acesso em 20/07/2016. Deve-se observar, contudo, que os dados oficiais de exportações não equivalem ao volume de vendas, uma vez que o que se contabiliza são os valores das obras levadas ao exterior com objetivo de comercialização, antes que as vendas sejam de fato fechadas. Assim, quando uma galeria vai participar de uma feira no exterior, são registrados os valores das obras que ela leva, e não o valor consolidado das vendas. Um aumento das exportações significa uma aposta das galerias no mercado internacional, mais do que um crescimento efetivo das vendas para o mercado internacional.
} 
É importante indagar de que forma, afinal, tais resultados estariam impactando outras esferas do sistema, em particular, as condições de produção e circulação da arte contemporânea. Quando o mercado passa por um período de crescimento, outras instâncias e agentes também são beneficiados/afetados? É fato que a pesquisa com as galerias tem apenas os agentes do mercado como protagonistas e não traz informações aprofundadas sobre os artistas, colecionadores e instituições, até porque esse não é seu escopo. Contudo, tais agentes são fundamentais para se pensar a dinâmica do sistema e do próprio mercado, existindo uma interdependência entre eles. E é justamente sobre essa interação que me parece fundamental refletir. Por isso, aqui não pretendo retomar globalmente os dados da pesquisa, que se encontram publicados, mas sim chamar a atenção para algumas informações que nos permitem refletir sobre os artistas, os colecionadores e as instituições, e trazer algumas informações qualitativas coletadas diretamente, em conversas e entrevistas com diferentes agentes envolvidos.

\section{O mercado e os artistas}

O mercado primário de arte contemporânea tem como foco, via de regra, a representação de artistas contemporâneos em atividade. $O$ trabalho de representação envolve uma série de atividades que contribuem para a construção e consolidação da carreira do artista, e culminam na comercialização do seu trabalho.

Entre as atividades das galerias identificadas na pesquisa estão: arquivamento e documentação das obras dos artistas, financiamento e produção de obras, edição e apoio a publicações, organização de exposições individuais, participação em feiras, realização de parcerias nacionais e internacionais para posicionar o trabalho dos artistas representados, apoio à participação em exposições institucionais, acompanhamento crítico da produção. Tais atribuições demandam tempo, recursos, equipes qualificadas e ampla rede de contatos. Envolvem estratégias de médio e longo prazo e por isso são consideradas investimento na carreira do artista.

Nesse sentido, as galerias acabam desempenhando uma dupla função: econômica e cultural, pois não só comercializam as obras como também documentam, promovem, mostram, circulam, preservam e fomentam a produção contemporânea, desempenhando funções que talvez devessem ser assumidas também pela esfera institucional.

As galerias que participaram da pesquisa representam um universo de cerca de mil artistas, incluindo artistas com carreiras altamente consolidadas e internacionalizadas, e também artistas em início de carreira, constituindo assim uma amostra relevante do universo dos artistas contemporâneos em atividade. As galerias representam em média 22 artistas, mas esse número pode variar de cinco a mais de quarenta artistas, dependendo de seu perfil e estrutura.

Desse universo de artistas representados, aqui nos interessa o percentual de novos artistas, ou seja, aqueles que entram no mercado pela primeira vez. Esse dado fala da capacidade das galerias de lançarem novos nomes, o que envolve um certo risco, mas é fundamental para a renovação e expansão do sistema da arte de forma mais abrangente, pois estimula uma maior circulação da produção artística emergente em outras esferas do circuito. A tendência é que o percentual de novos 
artistas acompanhe o movimento de expansão do setor e a criação de novas galerias, que se identificam com essa jovem produção. Nas quatro edições da pesquisa, o percentual de novos artistas variou de $23,6 \%$ a 3,5\%. Não por acaso, esse percentual foi maior em 2010 e 2011, quando várias novas galerias surgiram, e atingiu o menor valor em 2014. Esse índice mais baixo está, sem dúvida, relacionado não só ao contexto de instabilidade econômica atual, adverso a riscos e apostas (como investir em novos artistas que ainda não têm um mercado assegurado), mas também à necessidade de se investir na construção da carreira dos artistas integrados em anos anteriores, o que requer tempo e trabalho a mais longo prazo.

Atualmente, o mercado não está mais recrutando tantos artistas jovens e voltou a apostar em artistas com carreiras consolidadas como estratégia para enfrentar a crise. Os artistas já consolidados têm preços mais elevados, o que permite às galerias atuar no mercado internacional, cujos custos são altos, sobretudo face à desvalorização do real frente ao dólar. Alguns galeristas declaram, como Luisa Strina, focar em artistas reconhecidos a fim de compensar os altos custos das feiras internacionais ${ }^{13}$, plataformas importantes de negócios, sobretudo num momento em que o mercado nacional encolheu.

O contexto atual parece prejudicar justamente os artistas mais jovens, o que faz pertinente indagar acerca de quais plataformas de fomento à produção mais recente existem fora do mercado. São raras as instituições capazes de manter uma programação que contemple artistas em início de carreira. Papel importante têm os espaços independentes, mas eles atuam de forma irregular, dada a precariedade e a falta de recursos que os caracteriza de modo geral. Em inúmeras ocasiões, gestores desses lugares comentaram sobre o rápido movimento de absorção do mercado de artistas que eles expuseram pela primeira vez. Com um mercado mais conservador diante da crise econômica, o recrutamento de novos artistas tende a arrefecer e por essa razão é ainda mais importante se pensar em alternativas para fomentar e exibir a produção contemporânea.

É interessante entender também a forma como as galerias e os artistas se relacionam, e investigar se, de fato, estar no mercado permite aos artistas viverem de seu trabalho enquanto artistas e, em caso de crise, como essas relações se transformam. Segundo a pesquisa, os termos de representação são acordados entre a galeria e o artista, e o procedimento usual é a galeria manter as obras em consignação e pagar ao artista, em média, $50 \%$ do valor de venda. Esse percentual pode variar dependendo do grau de reconhecimento do artista e do fato de a galeria coproduzir a obra, ou não, prática essa cada vez mais comum, dada a própria natureza da arte contemporânea e sua relação com contextos específicos. Nesse sentido, as vantagens de se estar em uma galeria podem ser percebidas de modos diferentes: para alguns artistas, o importante de se estar numa galeria é a possibilidade de maior circulação, uma vez que elas têm contato com instituições e participam de feiras no exterior; outros destacam a possibilidade de ter assegurados recursos para produção de suas obras ${ }^{14}$.



${ }^{14}$ Os dados qualitativos a respeito da percepção e da relação dos artistas com o mercado fazem parte de uma nova pesquisa em curso, "O artista como trabalhador", uma parceria entre a autora deste artigo e a curadora Marta Ramos-Yzquierdo. Para mais informações sobre o projeto, contatar: analeticiafialho@gmail.com e martarye@gmail.com.
} 
A maioria das galerias mantém um misto de acordos verbais e contratos formais com seus artistas. Embora tenham informado, nas primeiras edições da pesquisa, estarem engajadas num processo de formalização das relações, o percentual de artistas representados formalmente e que têm contratos assinados com as galerias variou de $26 \%$ a $19 \%$. É interessante observar que o mais baixo índice é encontrado na última edição da pesquisa aqui tratada (2015), justamente quando o mercado começa a sofrer perante um contexto econômico instável. Quando há instabilidade, observa-se uma maior informalidade, há menos segurança nas relações e se evitam engajamentos mais a longo prazo. Algumas galerias atestaram também estar diminuindo o número de artistas representados, estabelecendo relações mais pontuais, organizando exposições de artistas não representados para ver se podem funcionar comercialmente, antes de decidir por sua representação.

Outro dado significativo que a pesquisa traz é o alto nível de internacionalização dos artistas: cerca de 50\% dos artistas representados por galerias brasileiras recentemente participaram de exposições e/ou foram adquiridos pelo mercado internacional, e aproximadamente $20 \%$ deles também são representados por galerias estrangeiras. Resta saber até que ponto o trabalho das galerias brasileiras tem de fato impulsionado uma maior circulação dos artistas mais jovens, e se a representação por galerias estrangeiras ajudará a compensar a retração das vendas para o mercado nacional. Será interessante acompanhar também o impacto da abertura de filiais de galerias brasileiras no exterior na trajetória dos artistas que representam ${ }^{15}$, mas por ser um fenômeno bastante recente, ainda é difícil avaliar.

Não obstante, é importante compreender de que forma a expansão recente do mercado impactou a forma como os artistas sobrevivem e como trabalham, e quais são as determinantes atuais da produção contemporânea. Nesse sentido, uma nova pesquisa em curso busca analisar o status do artista como trabalhador e as condições socioeconômicas de sua produção no Brasil ${ }^{16}$.

\section{O mercado e as instituições ${ }^{17}$}

Contrariamente à esfera de produção e do mercado, a esfera institucional não parece ter aproveitado da mesma forma o recente período positivo de expansão, fortalecimento e internacionalização, pois continua a enfrentar dificuldades na realização de funções essenciais como o fomento à produção, o desenvolvimento de pesquisa, a organização de exposições e o colecionismo da arte contemporânea.

É sintomático não existirem pesquisas consolidadas e continuadas sobre esse importante pilar do sistema ${ }^{18}$, mas alguns dados disponíveis, da própria Pesquisa

\footnotetext{
$\overline{15}$ Segundo a revista Veja, a galeria Nara Roesler abriu filial em Nova lorque, a Mendes Wood também deverá abrir uma filial na cidade e outra em Bruxelas, Marcelo Guarnieri deverá abrir filial em Lisboa e Emma Thomas está com um projeto pop up em Nova lorque. Ver: FLAMINGO, Juliana. Em movimento inédito, galerias paulistanas abrem filiais no exterior. Veja, 01 de jul. de 2016. Disponível em: http://vejasp.abril.com.br/materia/galerias-de-arte-paulistanas-exterior

16 "O artista como trabalhador", projeto de pesquisa já referido.

17 Parte da reflexão aqui apresentada sobre esse tema foi desenvolvida pela autora inicialmente no artigo "Política institucional: como construir coleções", publicado na Revista Select, no 27, (vide bibliografia).

18 O interesse em monitorar e analisar determinado setor é, em si, um sinal de sua relevância e amadurecimento, contudo, a produção de dados consistentes, sobre os diversos segmentos do sistema das artes no Brasil é ainda um desafio a ser enfrentado. Sobre a importância de estudos e pesquisas para balizar corretamente a elaboração de políticas públicas, ver Fialho e Goldstein (2012).
} 
Setorial Latitude, analisados à luz de outras pesquisas parciais realizadas em 2010 e $2015^{19}$, dão notícia de sua fragilidade.

Entre 2010 e 2014, o crescimento do mercado de arte contemporânea foi impulsionado em grande parte pelos colecionadores privados brasileiros, responsáveis por mais de $70 \%$ do volume de negócios, seguido pelos colecionadores privados estrangeiros, que movimentaram cerca de 13\%. Já as instituições brasileiras movimentaram no mesmo período, em média, $4 \%$ das vendas das galerias, seguidas de perto das instituições internacionais, responsáveis por cerca de $3 \%$. No período, foram identificadas mais de 100 coleções institucionais e corporativas estrangeiras que adquiriram obras de artistas brasileiros, algumas com bastante regularidade, como o MoMA e a Tate. Em 2014, pelo menos 130 obras de artistas brasileiros foram adquiridas por 24 instituições internacionais. A Tate, por exemplo, adquiriu recentemente a instalação Tropicália (1967), de Hélio Oiticica, avaliada em US\$ 5 milhões, e o MoMA está negociando outros trabalhos do artista, cujo preço médio de obras da década de 1960 chega a US\$ 1 milhão²0. É difícil imaginar uma instituição brasileira que possa fazer o mesmo tipo de investimento.

Esses dados sugerem que a produção contemporânea brasileira vem sendo incorporada em coleções privadas no Brasil e no exterior, e que tem despertado interesse crescente por parte das instituições e do mercado internacional. Já o colecionismo institucional nacional, de outra parte, mostra-se incipiente e infelizmente a tendência é que as instituições brasileiras fiquem cada vez mais defasadas em relação à produção contemporânea, nacional e internacional.

\section{Os colecionadores no museu ${ }^{21}$}

A importância dos colecionadores privados brasileiros fica evidente não só por sua capacidade de movimentar o negócio das galerias, fomentando indiretamente a produção contemporânea na medida que constituem e expandem suas coleções privadas, mas também como agentes fundamentais do colecionismo institucional. Comitês de aquisição, clubes de colecionadores, grupos de patronos... Os modelos e programas podem apresentar diferenças, não obstante, a captação de recursos junto a indivíduos com alto poder aquisitivo constituem a principal estratégia das instituições brasileiras para viabilizar aquisições.

Um exemplo de iniciativa desse gênero é o grupo de Patronos da Arte Contemporânea da Pinacoteca do Estado de São Paulo, criado em 2012, que tem por objetivo constituir um fundo de doações para aquisição de obras de arte brasileiras produzidas a partir de 1960. O grupo de patronos, atualmente composto por 70

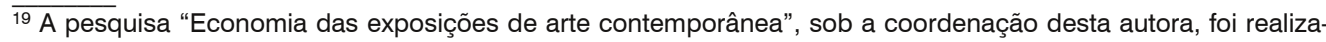
da em 2010, no âmbito de um convênio entre o Ministério da Cultura, a Fundação Iberê Camargo e o Fórum Permanente. Algumas informações estão disponíveis em: http://www.forumpermanente.org/.rede/ee. Infelizmente, tal pesquisa não teve os desdobramentos previstos devido à mudança de gestão do Ministério da Cultura em janeiro de 2011. A respeito, ver Fialho e Goldstein (2012), Fialho, Goldstein e Proença (2016) e Fialho (2014). Em 2015, como parte de uma pesquisa de pós-doutorado no Instituto de Estudos Brasileiros/USP e em preparação a um artigo publicado na revista Select, a autora levantou junto ao MAM do RJ, ao MAM de SP, à Pinacoteca do Estado de São Paulo e ao MAR, informações sobre suas estratégias de colecionismo da produção contemporânea.

${ }^{20}$ GONÇALVES FILHO, Antônio; MOLINA, Camila, 2016, op. cit.

${ }^{21}$ Cf. nota 16 
casais, arrecadou de 2012 a 2014, R\$ 1.956 .000 e possibilitou a aquisição de 17 obras de artistas contemporâneos ${ }^{22}$. Em 2015, a arrecadação parece ter ficado abaixo da média dos anos anteriores. Ainda assim, o programa constitui, segundo o seu diretor à época da entrevista, Tadeu Chiarelli, um dos pilares da política de aquisição do museu para arte contemporânea. Mesmo que relevante para a instituição, os valores investidos são irrisórios se comparados aos valores praticados no mercado e por instituições internacionais, basta pensar em artistas brasileiros consolidados, presentes em coleções de instituições internacionais, tais como Hélio Oiticica, Lygia Clark ou Cildo Meireles.

Exemplos de pedido direto de apoio a colecionadores para aquisições pontuais são também recorrentes e importantes, e complementam os programas regulares, que têm recursos limitados e trâmites via de regra mais demorados. É a eles que apelam as instituições quando identificam oportunidades que exigem decisões rápidas, obras raras que poderiam suprir lacunas da coleção ou ainda aquelas de alto valor. Segundo Chiarelli, existe uma nova geração de colecionadores que entendeu que as suas coleções só terão importância se as coleções institucionais forem significativas. Ora, isso evidencia o interesse e o entendimento dos colecionadores privados de que as instituições têm um importante papel na valorização simbólica e econômica dos artistas que exibem e colecionam.

Igualmente importantes e frequentes são as doações diretas de obras por artista e familiares e colecionadores, sujeitas sempre a um processo de avaliação pela direção, pela equipe curatorial e por conselhos consultivos.

Uma outra forma de associação das instituições com colecionadores privados é o regime de comodato, onde um colecionador privado coloca sob a tutela do museu uma coleção, condicionada ou não a futura doação. Por se tratar da entrada de um conjunto de obras colecionadas por indivíduos, segundo critérios subjetivos e individuais, em coleções institucionais, caberia indagar como se dá a relação entre as obras cedidas e a instituição, sua missão, suas linhas curatoriais e a coleção existente, e também qual o ônus que tais acordos podem trazer. O MAM-SP tem em comodato, por exemplo, obras da coleção de Eduardo Brandão e Jan Fjeld, sócios da galeria Vermelho. Há de se considerar, entretanto, que se não fossem tais acordos, seria praticamente impossível a entrada de conjuntos significativos de obras históricas e com alto valor de mercado em coleções institucionais, como é o caso da coleção Gilberto Chateaubriand em comodato no MAM RJ.

\section{O Estado e o colecionismo institucional}

Iniciativas que assegurem recursos públicos para aquisição de acervo, por outro lado, são bastante raras. Uma exceção é o Prêmio Marcantônio Vilaça, edital da Funarte/Minc, destinado ao fortalecimento de acervos de instituições culturais. Infelizmente, os recursos disponíveis diminuíram significativamente: em 2013, o prêmio tinha um orçamento de 2,9 milhões e contemplou 15 projetos; em 2015, em

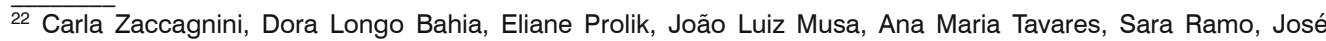
Damasceno, Sandra Cinto, André Komatsu, Delson Uchoa, Alexandre da Cunha, Eduardo Berliner, Erika Verzutti, Miguel Rio Branco, Maurício lanês e Nelson Felix (dados levantados até 2014).
} 
sua $8^{\text {a }}$ edição, teve um investimento de $R \$ 700$ mil reais, e beneficiou apenas 4 instituições (Museu de Arte Contemporânea da Universidade de São Paulo, Museu de Arte de Ribeirão Preto, Museu de Arte da Pampulha, Museu Nacional de Belas Artes). No atual contexto político, é difícil prever se esse edital continuará a existir.

Outra forma de aquisição relacionada a recursos federais, mas que também depende da captação de recursos junto à inciativa privada, é a Lei Rouanet, via de regra utilizada pelas instituições para aquisições pontuais de obras de alto valor.

Seria muito importante um maior investimento direto do Estado dotando as instituições de alguma autonomia orçamentária para aquisições, hoje inexistente. Também é responsabilidade do Estado a elaboração de políticas mais consistentes, de fomento à pesquisa e à programas expositivos experimentais, enfim, políticas voltadas ao fortalecimento da esfera institucional, que não deveria ficar tão vulnerável frente a interesses, em última instância, privados, sejam eles corporativos, mercadológicos ou individuais.

Em um cenário de recessão econômica, onde os recursos disponíveis se tornam mais escassos, e frente à inexistência de políticas e linhas de financiamento consistentes da parte do Estado, as instituições parecem cada vez mais apostar na participação dos colecionadores privados e do patrocínio de empresas para sanar lacunas e ampliar os seus acervos e ultimamente também para assegurar seus programas expositivos ${ }^{23}$. Sem o engajamento desses agentes, o colecionismo institucional no Brasil seria quase inexistente ${ }^{24}$.

Além de recursos públicos e uma maior autonomia, o colecionismo institucional também carece de linhas curatoriais claras e coerentes e de políticas públicas continuadas. A verdade é que a maioria das instituições brasileiras não está formando coleções abrangentes de arte contemporânea, que permitam conhecer as diferentes vertentes de nossa produção a partir do contemporâneo histórico até os dias de hoje. Além disso, dificilmente nossas coleções logram estabelecer alguma relação com a produção contemporânea internacional, pouco representada ${ }^{25}$. Tudo isso limita fortemente o potencial de nossas instituições participarem do processo de homologação e hierarquização dos valores artísticos e, em última instância, da escrita da história da arte no plano nacional e internacional.

\section{Considerações finais}

Infelizmente, o período globalmente positivo vivido pelo sistema da arte por pouco mais de uma década não culminou com o fortalecimento, profissionalização, expansão e internacionalização de todas as instâncias do sistema (formação, produção, crítica, instituições, circuitos associativos e mercado). A defasagem entre o

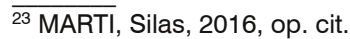

${ }^{24}$ Entendemos que é muito positivo o engajamento de indivíduos no fortalecimento das instituições públicas brasileiras. Por outro lado, o que parece preocupante é que as principais políticas de expansão dos acervos dependem forte ou exclusivamente da participação de colecionadores, muitas vezes, envolvidos também nos conselhos de administração das instituições. Não se pode deixar de observar que tais agentes são também importantes protagonistas do mercado de arte e têm interesse na valorização de suas próprias coleções.

25 À exceção talvez de Inhotim (MG), em que o número de artistas é bastante limitado e o colecionismo se concentra em nomes já consagrados, e da Pinacoteca do Estado de São Paulo, que tem uma política estruturada de aquisição mas que ainda não exibe um panorama da produção contemporânea.
} 
circuito institucional, o polo de produção e o mercado de arte persistem. A internacionalização e o amplo reconhecimento da produção artística brasileira é um processo positivo e irreversível, e o papel do mercado tem sido importante nesse sentido. Mas os artistas necessitam de plataformas e iniciativas que fomentem produção, circulação, pesquisa e experimentação, responsabilidade que o mercado, por sua própria natureza, não deveria assumir integralmente.

O problema consiste em não termos consolidado no Brasil um sistema das artes que fomente, pesquise, exiba, critique, publique e colecione a produção contemporânea, colocando-a em contexto e construindo narrativas próprias, de forma a estabelecer um diálogo horizontal com circuito internacional.

\section{Referências}

ALZUGARAY, Paula. Galeria Nara Roesler abre filial em Nova lorque. Lançamento oficial será durante a Armory Show 2016, em março. Select, São Paulo, 21 de jan. de 2016. Disponível em: <http://www.select.art.br/start-spreading-the-news/ Último acesso em 01/07/2016>

FIALHO, Ana Letícia. Pesquisa Setorial Latitude. O mercado de arte contemporânea no Brasil (4aㅡ edição). São Paulo: Latitude, 2015. Disponível em: <http://www.latitudebrasil.org/pesquisa-setorial/>

. Como construir coleções? Revista Select no 27, nov.-dez. de 2015, disponível em $<$ http://www.select.art.br/como-construir-colecoes/>

"O Ibram, o mercado de arte, os desacertos das políticas públicas e a salvaguarda do patrimônio

cultural nacional." Fórum Permanente, janeiro de 2014. Disponível em: $<$ http://www.forumpermanente.org/imprensa/instituto-brasileiro-de-museus-ibram/ibram-mercado-dearte-politicas-publicas-salvaguarda-patrimonio-cultura>. Último acesso em: 01 de julho de 2016.

. As pesquisas e suas lacunas. Os limites dos relatórios sobre o mercado brasileiro. Revista Select, ano 3, ago-set de 2013.

. Arte, um negócio sustentável. Revista Select, ano 2, ed. 07, ago-set de 2012.

"O Brasil está no mapa? Reflexões sobre a inserção e a visibilidade do Brasil no mapa internacional das artes". In: BUENO, Maria Lucia (org.). Sociologia das artes visuais no Brasil. São Paulo: Senac, 2012b, pp. 141-160.

"O mercado de arte e as instituições: uma aliança possível?" Fórum Permanente, 2011a. Disponível em: <http://www.forumpermanente.org/.event_pres/exposicoes/sp-arte-2011/relatos/omercado-de-arte-e-as-instituicoes> Último acesso em: 01 de julho de 2016.

Mercado de artes: global e desigual. Revista Trópico, mar./2005. Disponível em: <http://p.php.uol.com.br/tropico/html/textos/2551,1.shl> Último acesso em: 01 de julho de 2016.

FIALHO, Ana Letícia; GOLDSTEIN, Ilana. “'Economias’ das exposições de arte contemporânea no Brasil: notas de uma pesquisa”. In CALABRE, Lia (org.). Políticas culturais: pesquisa e formação. São Paulo: Fundação Casa de Rui Barbosa; Rio de Janeiro: Itaú Cultural, 2012, p.247-264.

. Conhecer para atuar. A importância de estudos e pesquisas na formulação de políticas públicas para a cultura. Revista Observatório Itaú Cultural, v. 1, p. 25-32. São Paulo: Itaú Cultural, 2012.

PROENÇA, Renata. "Economias da arte contemporânea Programação, financiamento e gestão em instituições culturais brasileiras.” In: VILLAS BÔAS, Gláucia; QUEMIN, Alain. (Org.). Arte e vida social: pesquisas recentes no Brasil e na França. 1ed.Marseille: Open Edition Press, 2016, v. 1, p. 1-10. 
FLAMINGO, Juliana. Em movimento inédito, galerias paulistanas abrem filiais no exterior. Veja, 01 de jul. de 2016. Disponível em: <http://vejasp.abril.com.br/materia/galerias-de-arte-paulistanas-exterior>

FRIAS, Maria Cristina. Venda de obras de arte cai, mas preço se mantém. Folha de São Paulo, São Paulo, quarta-feira, 17 de fev. de 2016.

GONÇALVES FILHO, Antônio. Arte para exportação. Estado de São Paulo, São Paulo, 21 de jan. de 2016.

MACIEL, Nahima. Arte exportação. Correio Brasiliense, Brasília, Domingo, 14 de fev. de 2016.

MARTI, Silas. Crise força museus a cortar mostras e aumentar duração de exposições. Folha de São

Paulo, São Paulo, 22 de mar. de 2016. Disponível em: <http://www1.folha.uol.com.br/ilustrada/2016/03/1752593-crise-forca-museus-a-cortar-mostras-eaumentar-duracao-de-exposicoes.shtml> Último acesso em: 20 de julho de 2016.

MOULIN, Raymonde. L'artiste, l'institution et le marché. Paris: Flammarion, 1992. . Le marché de l'art: mondialisation et nouvelles technologies. Paris: Flammarion, 2000.

QUEMIN, Alain. "The Internationalization of the Contemporary Art World and market: the role of nationality and territory in a supposedly 'globalized sector'”. In LIND, Maria; VELTHUIS, Olav (orgs.). Contemporary art and its commercial markets: a report on current conditions and future scenarios. Berlin: Sternberg Press; Spanga: Tensta Konsthall, 2012, pp. 53-84.

Recebido em 15/06/2017 - Aprovado em 21/08/2017 